\title{
Fluid Dynamics Analysis of a Novel Micropatterned Cell Bioreactor
}

\author{
Yuhong Cui, ${ }^{1}$ Bo Huo,,${ }^{2,3,4}$ Shujin Sun,,${ }^{2,3,4}$ Fan Yang, ${ }^{2,3,4}$ Yuxin GaO, ${ }^{2,3,4}$ Jun Pan, ${ }^{5}$ and Mian Long ${ }^{2,3,4}$ \\ ${ }^{1}$ Department of Mechanics, Tianjin University, Tianjin 300072, People's Republic of China; ${ }^{2}$ Key Laboratory of Microgravity, \\ Institute of Mechanics, Chinese Academy of Sciences, Beijing 100190, People's Republic of China; ${ }^{3}$ National Microgravity \\ Laboratory, Beijing 100190, People's Republic of China; ${ }^{4}$ Center for Biomechanics and Bioengineering, Institute of Mechanics, \\ Chinese Academy of Sciences, Beijing 100190, People's Republic of China; and ${ }^{5}$ Bioengineering College, Chongqing University, \\ Chongqing 400030, People's Republic of China
}

(Received 11 October 2010; accepted 10 January 2011; published online 20 January 2011)

Associate Editor Tingrui Pan oversaw the review of this article.

\begin{abstract}
Although flow-based bioreactor has been widely used to provide sufficient mass transportation and nutrient supply for cell proliferation, differentiation, and apoptosis, the underlying mechanism of cell responses to applied flow at single cell level remains unclear. This study has developed a novel bioreactor that combines flow bioreactor with microfabrication technique to isolate individual cells onto micropatterned substrate. A mechanical model has also been developed to quantify the flow field or the microenvironment around the single cell; flow dynamics has been analyzed on five geometrically different patterns of circle-, cube-, 1:2 ellipse-, 1:3 ellipse-, and rectangle-shaped "virtual cells." The results of this study have demonstrated that the flow field is highly pattern dependent, and all the hydrodynamic development length, cell spacing, and orientation of inlet velocity vector are crucial for maintaining a fully developed flow. This study has provided a theoretical basis for optimizing the design of micropatterned flow bioreactor and a novel approach to understand the cell mechanotransduction and cell-surface interaction at single cell level.
\end{abstract}

Keywords-Fluid dynamics, Cell bioreactor, Micropattern.

\section{LIST OF SYMBOLS}

$a, b, h$

ATR

$(c-a) / a=(d-b) / b$

$c, d$

$D$
Length, width, height of an isolated cell

Active test region

Spacing ratio

Length, width of an unit Hydrodynamic diameter $(=2 W H /(W+H))$
Address correspondence to Mian Long, Key Laboratory of Microgravity, Institute of Mechanics, Chinese Academy of Sciences, Beijing 100190, People's Republic of China. Electronic mail: mlong@ imech.ac.cn

Yuhong Cui and Bo Huo contributed equally to this work.
$\mathbf{F}_{\mathrm{b}}$

$L, W, H$

$L_{\text {inlet }}, L_{\text {outlet }}, L_{\text {wall }}$

$L_{\text {inlet }} / D, L_{\text {outlet }} / D$,

$L_{\text {wall }} / D$

$L_{\text {inlet }}^{\prime}, L_{\text {outlet }}^{\prime}, L_{\text {wall }}^{\prime}$

$p$

$p_{t}$

$Q$

Re

u

$\alpha, \beta, \gamma$
Body force per unit mass Length, width, height of a flow chamber

Inlet, outlet, wall length of a flow chamber

Non-dimensional hydrodynamic development inlet, outlet, wall length in a micropatterned flow chamber Applied inlet, outlet, wall length in a flow chamber when the computation is need Pressure of flow field Relative pressure Flow flux of flowing fluid Reynolds number Velocity vector of flowing fluid

Non-dimensional hydrodynamic development lengths of inlet, outlet, wall in a cell seeded flow chamber

\section{$\Theta, \nabla$}

$\mu$

$\rho$ Substantive derivative, vector differential operator Dynamic viscosity of flowing fluid Mass density of flowing fluid

\section{INTRODUCTION}

Biofluid flow, e.g., interstitial flow in osteocyte lacunae or cartilage proteoglycan network or shear flow in blood vessels, is crucial in many biological processes in vivo. Flow chamber is a well-defined in vitro model to mimic the physiological conditions 
for elucidating the effect of biofluid flow on cellular responses such as cell proliferation, ${ }^{17,33}$ apoptosis, ${ }^{24}$ differentiation ${ }^{1,28}$ migration, ${ }^{35}$ adhesion, ${ }^{29}$ cell interaction in co-culture, ${ }^{5}$ and intra/intercellular signalings. ${ }^{16,31,40}$ Flow chamber also serves as a cell/tissue bioreactor in space cell biology to maintain cellular metabolism under microgravity, ${ }^{32}$ since the refreshment of culture medium, a conventional procedure under ground-based conditions, becomes complicated and hard to perform in space and should be automatically done via continuous perfusion in a closedloop system. In the past decades, different types of flow chambers or flow-based bioreactors have been developed mainly with parallel-plate flow approach, where cells are seeded on the bottom plate and grown to a confluent monolayer while the medium is driven to flow over cells providing sufficient nutrient supply and mass transportation.

Fluid dynamics inside the chamber or bioreactor is critical to quantify the impact of shear flow on cellular responses. Although extensive theoretical analyses and calculations have been conducted in the absence of growing cells, ${ }^{4,9,11,30}$ little is known as to how the presence of cell monolayer affects the hydrodynamic parameters of flow field, e.g., static pressure, shear stress, or strain rate, around the cells. In previous studies, a few fluid mechanics models were proposed to predict the flow field at the vicinity of curved endothelial cell monolayer in blood vessel, ${ }^{15,22}$ and the wall shear stress was found to vary more than $80 \%$ across the chamber because of the so-called end effects. ${ }^{40}$ Moreover, growing cells are highly sensitive to the alterations of hydrodynamic parameters, for example, alkaline phosphatase activity increases dramatically with shear stress in engineered bone tissue,,$^{3,13,14,16,19,31,40}$ and intracellular process and cell body respond differentially to various mechanical loadings. ${ }^{21}$ Thus, fluid dynamics analysis is a prerequisite to monitor the hydrodynamic parameters, such as flow flux, velocity, and shear stress, and to understand the mechanism of cell mechanotransduction.

Recent progresses in microfabricating techniques make it possible to understand the biological responses of an isolated cell to external forces. In contrast to the confluent cell monolayer where physical linkages and gap junctions exist among cells, an isolated cell is micropatterned on a hydrophilic island without the impact of cell-cell contact, which enables us to quantify cellular mechanotransduction responses at single cell level. ${ }^{8,15,18,20}$ For example, intracellular calcium response to shear flow of isolated osteoblasts on micropatterned islands was found to be quite different from that of the osteoblasts in a confluent monolayer. ${ }^{16,31,40}$ The shape and size of hydrophilic island designed to confine the spreading configuration and contact area of a cell resulted in distinct phenotypes in apoptosis, differentiation, and proliferation of mesenchymal stem cells. ${ }^{7}$ Microfabricating technique with micropatterned cells is especially beneficial for a cell bioreactor used in space life science where the impact of shear flow from continuous perfusion is coupled with the effect of microgravity. The cellular responses in space are more complicated than that on ground, and understanding the responses of an isolated cell to microgravity is a basic issue for space cell biology. To better understand the mechanotransduction mechanism of an isolated cell, the flow field around those individual cells needs to be further determined by fluid dynamics analysis.

Computational fluid dynamics (CFD) is a powerful tool to visualize the flow field in a specific configuration $^{4}$ or an interstitial space of a flow chamber, which has provided hydrodynamic basis to design the threedimensional (3D) bioreactor in tissue engineering. ${ }^{34}$ This has been demonstrated to be working very well in the uniform cell growth under well-designed 3D geometry, ${ }^{19}$ in the sufficient perfusion to cells cultured in configuration-optimized biomaterial scaffolds, ${ }^{27}$ or in the identification of proper boundary conditions for a microscale model. ${ }^{11}$ In a recent study, the authors developed a bioreactor for counter sheet-flow sandwich cell culture which was used in a space cell biology experiment under microgravity where fluid dynamics analysis illustrated the symmetrical velocity profile and uniform distribution of low strain rate for mammalian cell growth. ${ }^{32}$ In this article, a novel micropatterned cell bioreactor, in which the flow field is quite different from those in the literature, has been proposed, and the hydrodynamic profiles around the micropatterned cell have been determined.

\section{THEORETICAL MODELING}

\section{Configuration and Geometry}

The basic idea of developing the micropatterned cell bioreactor started from a parallel-plate flow chamber (Fig. 1a) which exerts fluid flow on the micropatterned osteoblast monolayer without physical intercellular connection (Fig. 1d). As exemplified in the schematics of the bioreactor and its configuration and geometry (Fig. 1b), the fluid was driven to flow through a parallelplate rectangular chamber with the dimension of $L$ (length) $\times W$ (width) $\times H$ (height). The hydrodynamic development lengths of inlet, outlet, and wall for a fully developed flow were denoted as $L_{\text {inlet }}, L_{\text {outlet }}$, and $L_{\text {wall }}$, respectively. The active test region (ATR) with the area of $\left(L-L_{\text {inlet }}-L_{\text {outlet }}\right) \times\left(W-2 L_{\text {wall }}\right)$ was defined, within which the impacts of inlet, outlet, and chamber wall on flow field were negligible (Fig. 1b). ${ }^{11}$ The 
(b)

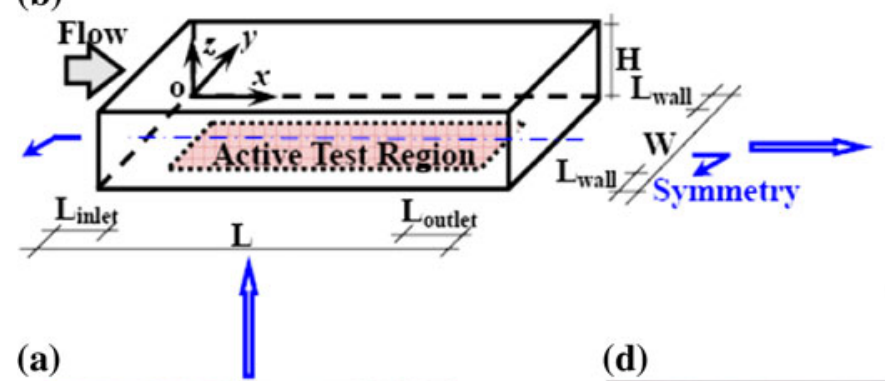

(c)

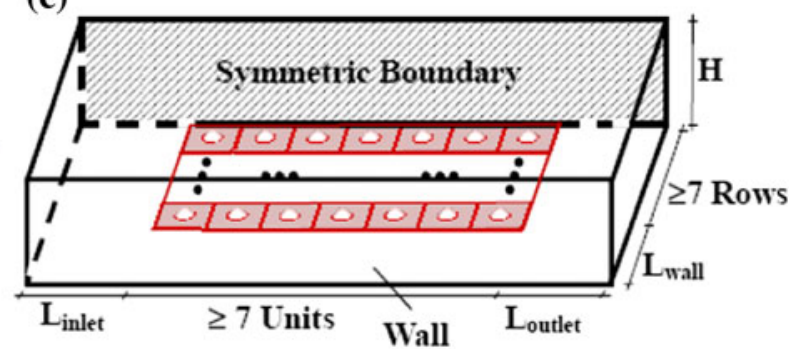

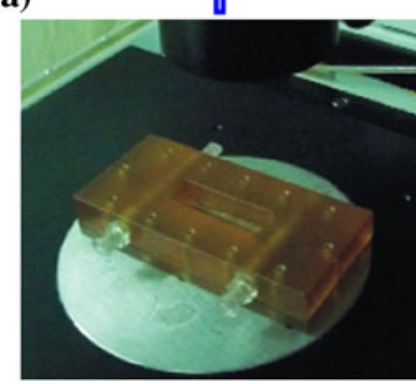
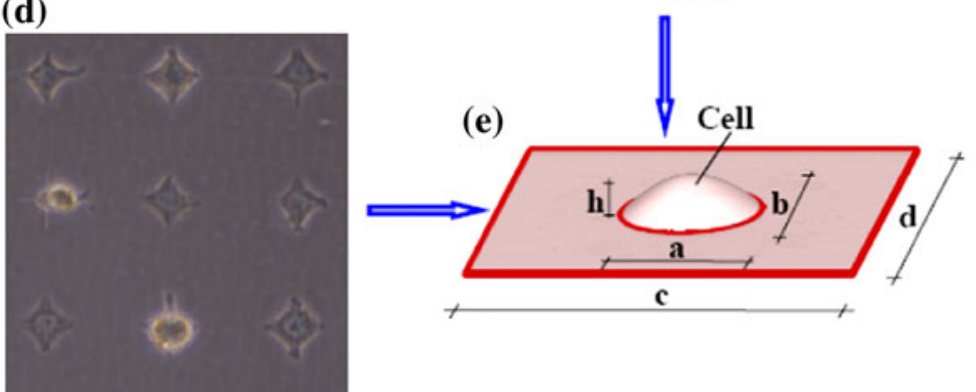

FIGURE 1. Schematics of a flow chamber (a), its computing model (b), a half computing model with active test region (c), micropatterned osteoblasts (d), and a unit with a single cell of computational model (e). In the current models, seven or fifteen units were placed in one row, and seven rows were used for simplicity of calculation.

boundary conditions of flow chamber along the transverse direction are symmetric, and therefore, the calculations are simply done with half of the chamber (Fig. 1c). The bottom plate inside ATR was micropatterned with numerical units (Fig. 1c). Along a row, each unit was assigned with a rectangular geometry with length of $c$ and width of $d$ onto which an isolated cell with occupied dimensions of $a$ (length) $\times b$ (width) $\times h$ (height) was placed (Fig. 1e). Five micropatterns were employed to mimic the isolated cells in the calculations, which were in the shape of circle (Cir)-, cube (Cub)-, 1:2 ellipse (El2)- (1:2 is the ratio between short and long axes), 1:3 ellipse (El3)-, or rectangle (Rec) from a top (upper panels) or a side (lower panels) view (Figs. 2a-2e). The circle-shaped pattern represents a seeded cell without spreading, and the ellipse-pattern (1:2 or 1:3) mimics the cells at different spreading level, whereas the cube- or rectangle-pattern serves as control. To make the calculations comparable, ${ }^{16}$ five types of micropatterned "virtual cells" were set to yield the same height and projected area under identical units as summarized in Table 1 . Each cell was assigned a $h$ of $0.5 \mu \mathrm{m}$ and a unit area of $10,000 \mu \mathrm{m}^{2}$, and the dimensions of $a$ and $b$ were then determined. Note that the projected area of a cell was not exactly the same among five micropatterns, mainly due to the differences in arc area.

\section{Governing Equations and Numerical Calculations}

Although an analytic solution of flow filed inside a rectangular chamber with smooth surface on bottom plate was readily obtained (cf. Supplementary Materi$a l s$, it was not applicable to a chamber seeded with isolated cells due to the impact of cell shape and dimension. Therefore, a novel mechanical model was developed in this study to conduct the CFD calculations on micropatterned cell surface ( $c f$. Fig. 1). In this study, flow medium in the chamber was modeled as incompressible Newtonian fluid under isothermal and non-slip boundary conditions. Referring to rectangular Cartesian coordinates, Navior-Stokes equation and mass conservation equations satisfy.

$$
\left\{\begin{array}{l}
\frac{\Theta \mathbf{u}}{\Theta t}=\mathbf{F}_{\mathrm{b}}-\frac{1}{\rho} \nabla p+\mu \nabla^{2} \mathbf{u} \\
\nabla \cdot \mathbf{u}=0
\end{array}\right.
$$

where $\mathbf{u}$ is the velocity vector, $p$ is the pressure, $\mu$ is the dynamic viscosity, $\rho$ is the mass density, $\mathbf{F}_{\mathrm{b}}$ is the body force per unit mass, and $\Theta$ and $\nabla$ are the substantive derivative and vector differential operators, respectively. The authors applied the boundary condition generally used in fluid dynamics simulation, i.e., uniformly distributed velocity at inlet section and constant flux $Q$ at outlet. Although the inlet boundary condition is a strong hypothesis, our additional simulations showed that the flow field around cells adhering on the bottom substrate of flow chamber is dependent on the flux, but insensitive to the inlet velocity profile.

Numerical calculations of flow field around a micropatterned cell in a flow chamber were conducted using finite volume method with second-order accuracy and double-variable precision. ${ }^{25}$ The commercial 

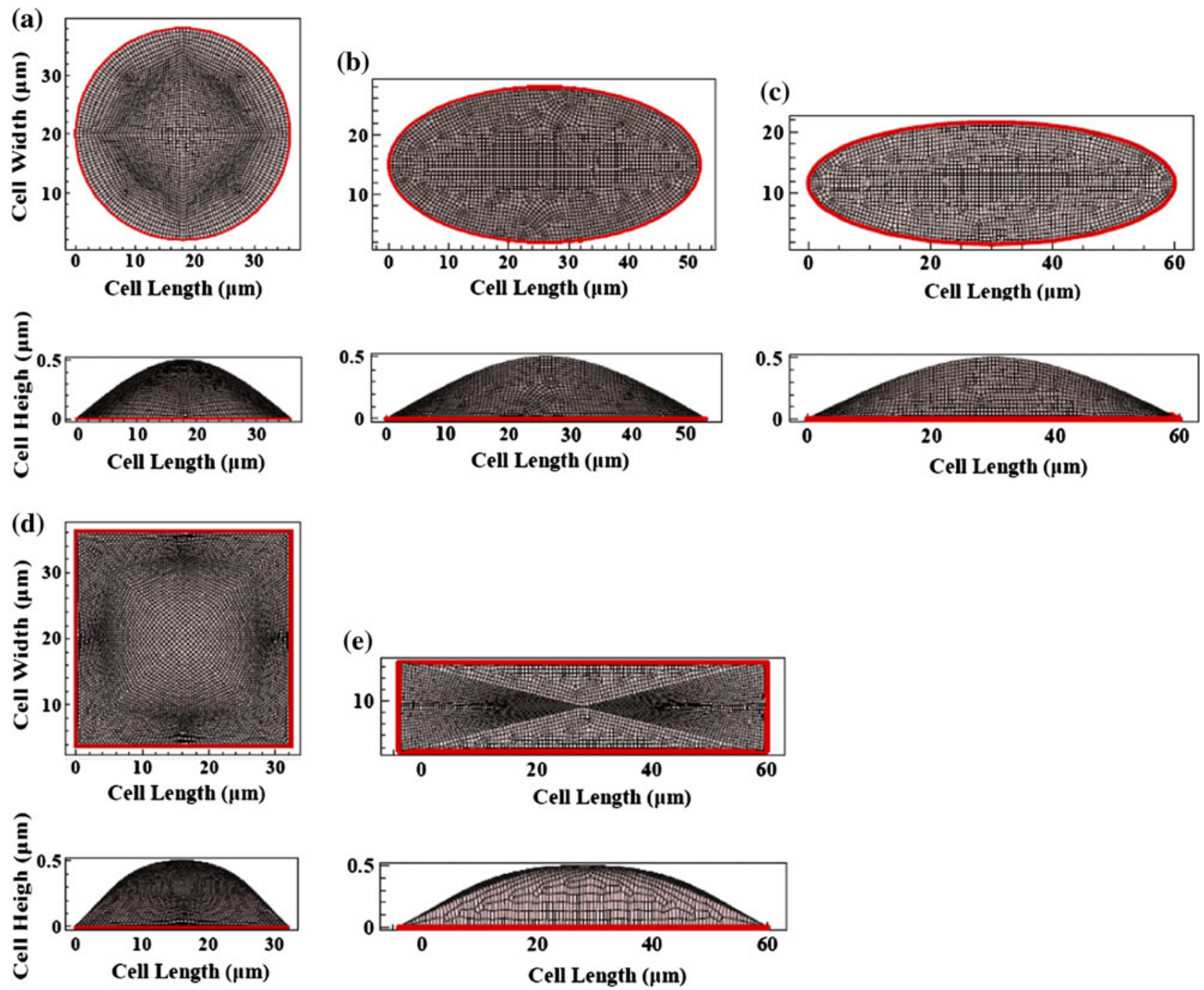

(e)
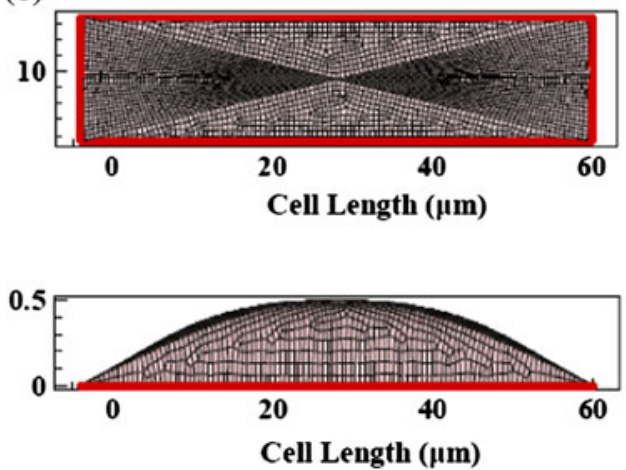

FIGURE 2. Five micropatterns with circle-(a), ellipse-(1:2) (b), ellipse-(1:3) (c), cubic-(d), and rectangular-shaped (e) surfaces were visualized from a top (upper panels) or a side (lower panels) view to mimic an isolated cell in an element (a-e) where the average of $45 \times 45$ elements were used for a cell in the calculations.

TABLE 1. Geometries of five micropatterned cells and elements.

\begin{tabular}{lrrrrr}
\hline Parameters & \multicolumn{1}{c}{ Cir } & \multicolumn{1}{c}{ El2 } & El3 & Cub & Rec \\
\hline Cell length, $a(\mu \mathrm{m})$ & 36.0 & 52.0 & 60.0 & 32.0 & 64.0 \\
Cell width, $b(\mu \mathrm{m})$ & 36.0 & 26.0 & 20.0 & 32.0 & 15.6 \\
Cell height, $h(\mu \mathrm{m})$ & 0.5 & 0.5 & 0.5 & 0.5 & 0.5 \\
Unit length, $c(\mu \mathrm{m})$ & 100.0 & 100.0 & 120.0 & 100.0 & 128.0 \\
Unit width, $d(\mu \mathrm{m})$ & 100.0 & 100.0 & 83.3 & 100.0 & 62.5 \\
Projected area of cell $\left(\mu \mathrm{m}^{2}\right)$ & 1000.5 & 997.0 & 989.7 & 998.6 & 998.4 \\
Area of unit $\left(\mu \mathrm{m}^{2}\right)$ & 10000.0 & 10000.0 & 10000.0 & 10000.0 & 10000.0 \\
\hline
\end{tabular}

CFD software, FLUENT, was employed to analyze the finite volume solver. Furthermore, an interface program was developed in-house to meet the computational requirements and used in the calculation of the fully developed flow at inlet section. Eight-node hexahedral elements were employed in the calculations to ensure the accuracy. Table 2 summarized the surface mesh number of single cells with different micropatterned shapes (Figs. 2a-2e). One unit was divided into $\sim 20,000$ surface elements and $\sim 35,000$ surface nodes, and totally $18,000,000-22,000,000$ elements were used. The computation was done using two computer stations of DELL PRECISION T5400 paralleled, and costs 1 day for less than $8,000,000$ units or 
3-5 days for more than $20,000,000$ units. Pure water with a density $(\rho)$ of $993.4 \mathrm{~kg} / \mathrm{m}^{3}$ and a viscous coefficient $(\mu)$ of $0.69 \mathrm{mPa}$ s served as flowing fluid. ${ }^{36}$ The temperature $(T)$ was set at $37{ }^{\circ} \mathrm{C}$, relative pressure $\left(p_{t}\right)$ was given at $1 \mathrm{~atm}$, and inlet volume flux $(Q)$ ranged from 2 to $500 \mu \mathrm{L} / \mathrm{min}$.

\section{Simplified Models and Simplified Calculations}

Simplified models were introduced into the above mentioned CFD calculations and were developed to calculate around micropatterned cells in the flow chamber with the dimensions of $L \times W \times H=$ $22 \times 6 \times 0.5 \mathrm{~mm}$, as referred in our previous study. ${ }^{16}$ Based on the symmetry of flow field, only half of the chamber was adopted in simulation (Fig. 1c). Since the cell height $(h)$ was far shorter than the height $(H)$ of the flow chamber $(h: H=1: 1000), H / 2$ was used as model height to reduce the computational costs, i.e., the symmetric boundary conditions were taken from the section at $H / 2$, while the boundary conditions at inlet and outlet remained unchanged. The hydrodynamic development lengths of inlet, outlet, and wall $\left(L_{\text {inlet }}\right.$, $L_{\text {outlet }}$, and $\left.L_{\text {wall }}\right)$ were calculated based on this model. To further simplify the flow field parameters of single cell, the cells were assumed to line up in one row, as previously described by Provin et al. ${ }^{27}$ The influence of different developing sections was neglected in the calculations, the height of flow chamber was set as $25 h$, the fully developed flow speed calculated through UDF interface program was used as inlet boundary condition, and the outlet boundary condition remained unchanged. Under such conditions, the computational

TABLE 2. Surface mesh number of hexahedral elements and surface nodes of one cell for different micropatterns.

\begin{tabular}{lcrrrr}
\hline & Cir & El2 & El3 & Cub & Rec \\
\hline Surface elements & 2916 & 1640 & 932 & 3844 & 1079 \\
Surface nodes & 3619 & 3066 & 2640 & 5458 & 3977 \\
\hline
\end{tabular}

time was significantly reduced, and the maximum error of flow velocity was less than $0.001 \%$.

It was also possible to reduce the number of cells placed in one row (originally $\sim 220$ cells were seeded along the chamber length $(L)$ of $22 \mathrm{~mm})$, because the flow field around the most of the cells within ATR should be identical. The authors tested the numerical calculations when seven and fifteen cells were placed in one row and found that the maximum relative error in static pressure and shear stress or strain rate on cell surface was $1.3 \%$ for the centered cell (Table 3). Therefore, the procedure with seven cells in one row was used in the calculations to be used later. The authors also tested the impact of row number and found that the error of average strain rate of cells between seven rows and ten rows is less than $1.0 \%$. Thus, seven rows were employed in these calculations.

An empirical formulation described previously was used to calculate the non-dimensional hydrodynamic development inlet length $L_{\text {inlet }} / D{ }^{2}$

$$
L_{\text {inlet }} / D=0.3125+0.011 R e,
$$

where $D$ is the hydrodynamic diameter, and $R e$ is the Reynolds number. For a cell-free flow chamber, $L_{\text {inlet }}$ could be calculated analytically using Eq. (2). However, when cells were micropatterened onto the bottom plate, these equations were no longer applicable and the $L_{\text {inlet }}, L_{\text {outlet }}$, and $L_{\text {wall }}$ should be calculated using the second model. To simplify the calculations, three coefficients, $\alpha, \beta$, and $\gamma$, respectively for non-dimensional $L_{\text {inlet }}, L_{\text {outlet }}$, and $L_{\text {wall }}$ in a cell-free flow chamber were introduced into Eq. (2) to evaluate the impact of micropatterned cells on CFD calculations, to result as follows:

$$
\begin{gathered}
L_{\text {inlet }} / D=\alpha(0.3125+0.011 R e), \\
L_{\text {outlet }} / D=\beta(0.3125+0.011 R e), \\
L_{\text {wall }} / D=\gamma(0.3125+0.011 R e) .
\end{gathered}
$$

\begin{tabular}{|c|c|c|c|c|c|c|}
\hline Parameters & Number of cells ${ }^{a}$ & Cir & El2 & $E / 3$ & Cub & $\operatorname{Rec}$ \\
\hline \multirow[t]{2}{*}{ Maximum average static pressure (mPa) } & 7 & 8.938 & 8.578 & 8.423 & 9.012 & 9.040 \\
\hline & 15 & 8.771 & 8.406 & 8.247 & 8.842 & 8.870 \\
\hline \multirow[t]{2}{*}{ Minimum average static pressure (mPa) } & 7 & 0.901 & 0.903 & 0.909 & 0.895 & 0.900 \\
\hline & 15 & 0.730 & 0.727 & 0.730 & 0.725 & 0.731 \\
\hline \multirow[t]{2}{*}{ Average shear stress (mPa) } & 7 & 0.169 & 0.159 & 0.159 & 0.172 & 0.168 \\
\hline & 15 & 0.159 & 0.153 & 0.153 & 0.160 & 0.158 \\
\hline \multirow[t]{2}{*}{ Average strain rate $\left(s^{-1}\right)$} & 7 & 0.103 & 0.101 & 0.101 & 0.104 & 0.103 \\
\hline & 15 & 0.103 & 0.101 & 0.101 & 0.104 & 0.103 \\
\hline
\end{tabular}

In line with the above, $L_{\text {wall }}$ was calculated using the second model. In contrast to direct adoption from a

TABLE 3. Calculated hydrodynamic parameters for different micropatterns.

${ }^{\mathrm{a} C e l l}$ number placed in one row within ATR. 
cell-free parallel-plate chamber where the centerline velocity reached $99 \%$ of the fully developed value, ${ }^{6,26}$ $L_{\text {wall }}$ in this study was so defined that the error between local strain rate on individual cell surface within ATR and the average strain rate on all the cell surfaces across the computed flow chamber is less than $1.0 \%$. Starting from a preset $L_{\text {wall }}^{\prime}$ in a cell-free rectangular chamber ( $c f$. Supplementary Materials), an iterative calculation was repeated to identify the reasonable $L_{\text {wall }}$ in a step size of $100 \mu \mathrm{m}$ until the relative error between the prescribed and the calculated $L_{\text {wall }}^{\prime}$ values was less than $1.0 \%$. Once $L_{\text {wall }}$ was obtained, $L_{\text {inlet }}$ (or $L_{\text {outlet }}$ ) was then determined with the given $L_{\text {wall }}$ and the preset $L_{\text {outlet }}^{\prime}$ (or $L_{\text {inlet }}^{\prime}$ ) from above iterative calculations.

\section{RESULTS}

\section{Flow Field Around Micropatterned Cells}

The authors have first tested the local hydrodynamic parameters including static pressure, shear stress, and strain rate on cell surface and the bulk velocity of flowing fluid around cells, which are crucial to cell function inside a flow chamber or a bioreactor. Numerical calculations from simplified model indicate that, when cells are micropatterned in different shapes, fluid flow produces significantly different distributions around cells. As shown in Fig. 3, the static pressure in the upstream is $\sim 2.0 \%$ greater for all the five cell shapes than that in the downstream at a flux of $2 \mu \mathrm{L} / \mathrm{min}$ (1st column), and the gradient of static pressure gradually reduces from the top to the bottom of cell. Shear stress and strain rate on cell surface as well as flow velocity are distributed symmetrically and vary dramatically across the cell (2nd, 3rd, and 4th columns, respectively). For example, shear stress and strain rate are enhanced from 0.09 to $0.11 \mathrm{mPa}$ and from 0.14 to $0.26 \mathrm{~s}^{-1}$, respectively; flow velocity is reduced from 0.070 to $0.005 \mathrm{~m} / \mathrm{s}$ from exterior edge to central top of a circle-shaped cell (1st row). The distributions of the hydrodynamic parameters, except that of static pressure, strongly depend on the microtpatterned cell shapes.

The authors further tested the average values of static pressure, shear stress, and strain rate on cell surfaces along the flow direction. The computing model was used at a flux of $2 \mu \mathrm{L} / \mathrm{min}$ and both $L_{\text {inlet }}^{\prime}$ and $L_{\text {outlet }}^{\prime}$ of $2000 \mu \mathrm{m}$. The linear law of fluid dynamics is satisfied for a single row of cells within ATR, since the fluid inertia is much less than fluid viscosity when $R e$ is as low as 0.023 in the model (Fig. 4). The average static pressure in a row of seven cells declines linearly with the distance from inlet at a slope of $\sim 0.00045 \mathrm{mPa} / \mathrm{m}$ (panel a), while average shear stress and strain rate on cell surface remain the same (panels $b$ and $c$ ). The average values of the three hydrodynamic parameters vary significantly with different cell patterns. For example, average pressure, shear stress, and strain rate of El2 and El3 patterns (blue and orange lines) are much lower than those of Cir, Cub, and Rec patterns (red, green, and pink lines, respectively, in panels $a-c$ ). It is also observed that the hydrodynamic parameters on cell surface are significantly enhanced than those at the bottom plate in a cell-free chamber ( $N o$ for black lines in panels $a-c$ ). The static pressure, shear stress, and strain rate are increased by $14.6 \%, 5.1 \%$, and $19.9 \%$, respectively as compared to the estimations (cf. Supplementary Materials). Similar results are obtained with different micropatterned cells when fifteen cells are in a row (data not shown). Numerical calculations also indicate that the linear relationships of the three hydrodynamic parameters are not altered at the respective fluxes of 2 , 50 , or $500 \mu \mathrm{L} / \mathrm{min}$ (with maximum relative error of $\sim 0.8 \%$ ). Such linear gradient enables us to optimize the hydrodynamic parameters in the chamber and the shear stress on cell surface.

The cellular spacing is another important factor that regulates cell function and intercellular signaling. When cells are micropatterned in a flow chamber, it is reasonable to assume that the space between adjacent cells affects the flow field. Thus, the dependence of hydrodynamic parameters on the spacing ratio $(=(c-a) / a$ or $(d-b) / b)$ was tested in this study. As exemplified in Fig. 5, average maximum static pressure exposed on cell surface decreases dramatically from 18.9 to $7.8 \mathrm{mPa}$ (153.5\% difference, pink line), but average shear stress and strain rate on cell surface only decrease slightly $(1.9 \%$ and $8.4 \%$ differences, respectively, blue and green lines), when the spacing ratio increases from 0.1 to 5.0. Even at the lowest ratio of 0.1 , the average maximum static pressure, shear stress, and strain rate are about 2.4-, 1.1- and 1.2-fold higher in the current calculations than those calculated based on a cell-free chamber (cf. Supplementary Materials). Thus, these results indicated that high cell density with low spacing ratio (also with small size of cells) results in high static pressure and shear stress on cell surface.

\section{Impact of Hydrodynamic Development Length}

For cells growing in a chamber or a bioreactor, the impact of inlet, outlet, and wall on hydrodynamic parameters should be taken into account. In this model $(L \times W \times H=22 \times 6 \times 0.5 \mathrm{~mm}$ and $Q=$ $2-500 \mu \mathrm{L} / \mathrm{min}$ ), with given hydrodynamic diameters $D$ $(=2 \mathrm{WH} /(W+H))$ of $0.92 \mathrm{~mm}$ and $R e$ of $0.015-5.83$, three coefficients $\alpha, \beta$, and $\gamma$ were calculated with a relative error less than 0.35 (Table 4). Here, the relative 


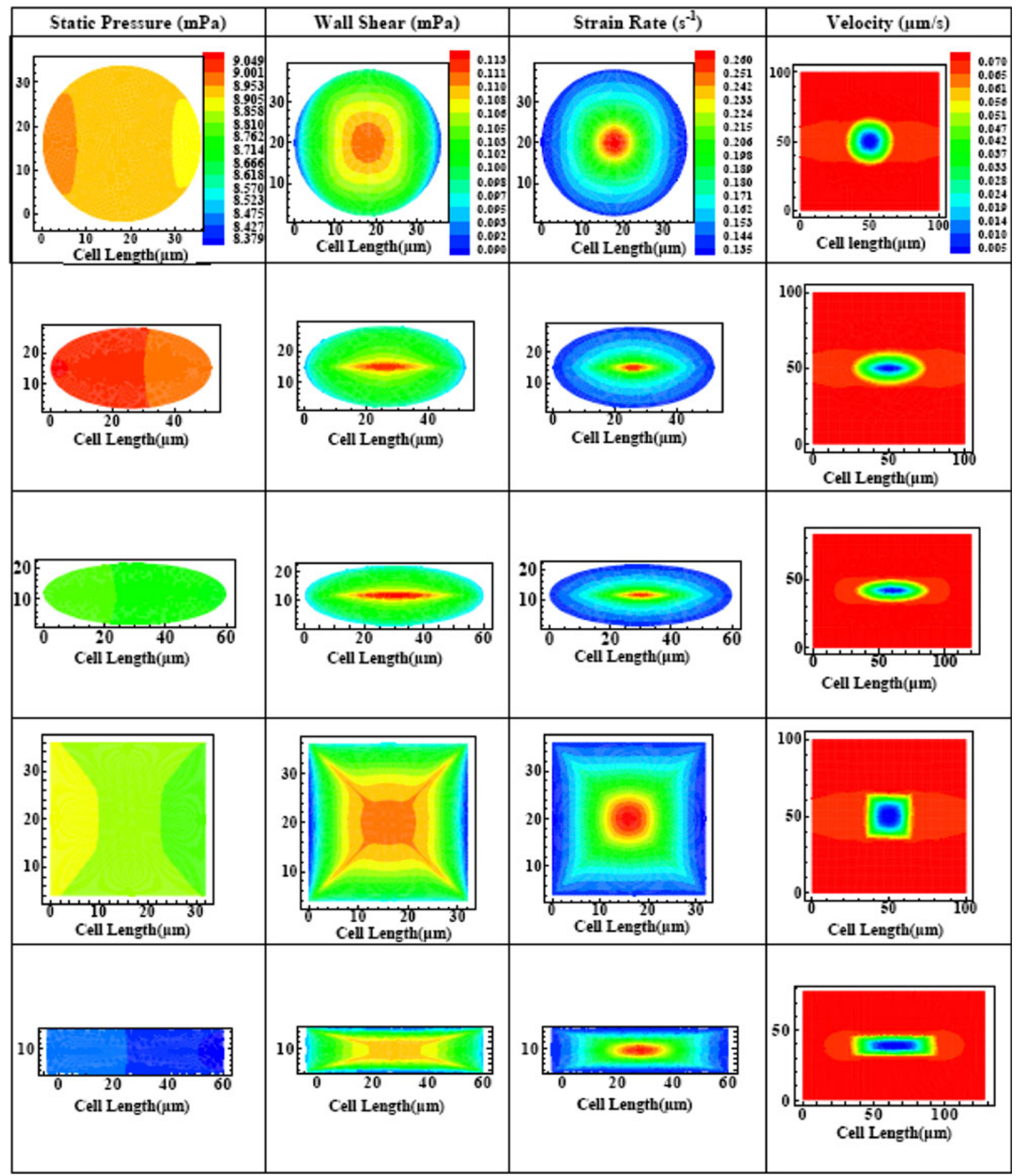

FIGURE 3. Fluid dynamics calculations of static pressure (1st column), shear stress (2nd column) and strain rate (3rd column) on cell surface, and flow velocity (4th column) around a micropatterned cell with a shape of circle (1st row), ellipse (1:2) (2nd row), ellipse (1:3) (3rd row), cube (4th row), and rectangle (5th row) at a flux of $2 \mu \mathrm{L} / \mathrm{min}$. Note that the dimensions of micropatterned cells were given in the 1st, $2 \mathrm{nd}$, and $3 \mathrm{rd}$ columns while the dimensions of units were denoted in the 4th column where the cross section paralleled to the top of cells.

error is defined as the percentage of computational maximal error to computational average value. $L_{\text {inlet }}$, $L_{\text {outlet}}$, and $L_{\text {wall }}$ were then directly calculated by
Eqs. (3a-3c) and Table 4. In a Cir-patterned chamber, for example, $L_{\text {inlet }}=800$ and $960 \mu \mathrm{m}, L_{\text {outlet }}=600$ and $720 \mu \mathrm{m}$, and $L_{\mathrm{wall}}=1000$ and $1200 \mu \mathrm{m}$ at $Q=2$ 
(a)
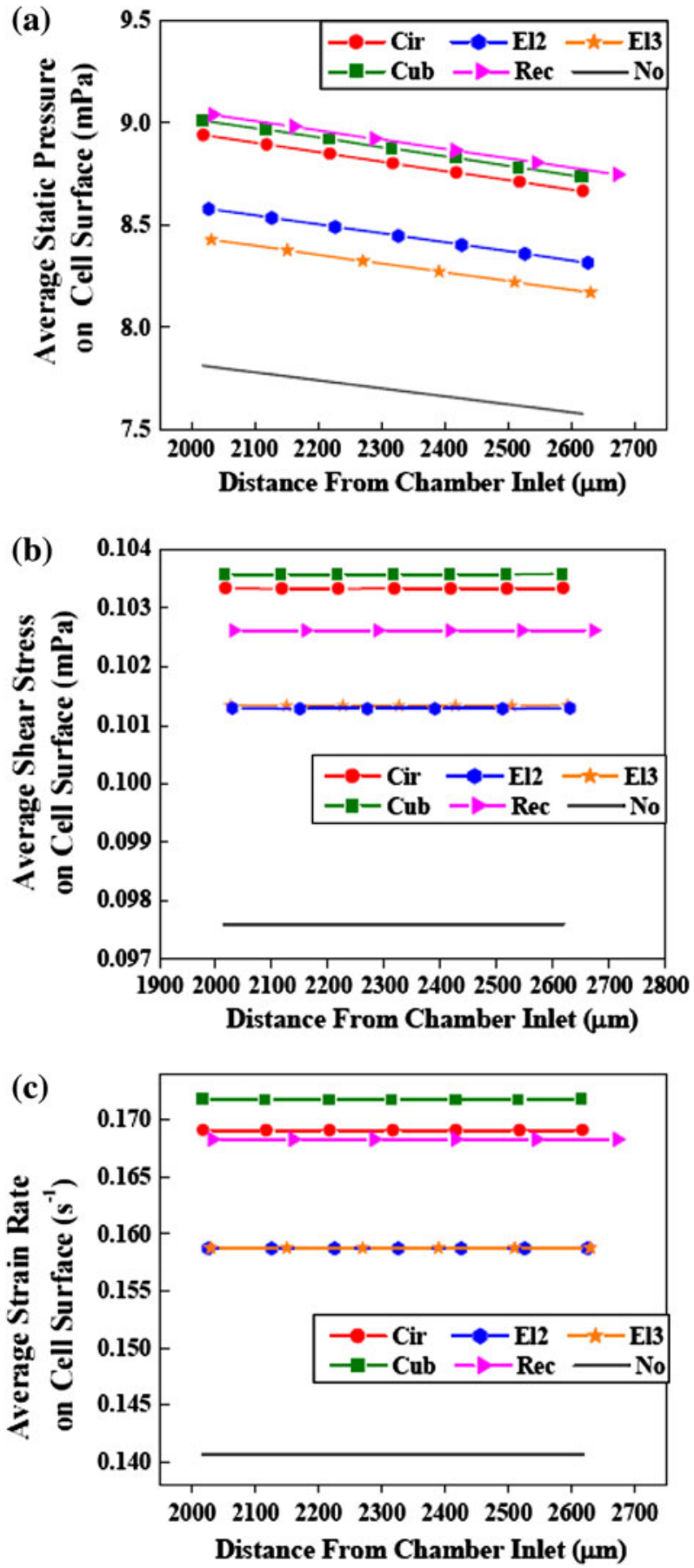

FIGURE 4. Fluid dynamics comparisons of average static pressure (a), shear stress (b), and strain rate (c) on the surface of a cell micropatterned as circle-(Cir in red), ellipse-(1:2) (El2 in blue), ellipse-(1:3) (E/3 in orange), cube-(Cub in green), rectangle-(Rec in pink), and none-(No in black) shaped cylinder at $2 \mu \mathrm{L} / \mathrm{min}$. The length of fully developed flow was set to be $2000 \mu \mathrm{m}$ from inlet or outlet.

and $500 \mu \mathrm{L} / \mathrm{min}$, respectively, indicating that outlet length is less than inlet length, and wall length has the greatest value (i.e., $L_{\text {outlet }}<L_{\text {inlet }}<L_{\text {wall }}$ ). Similar observation has been also confirmed with El2- or

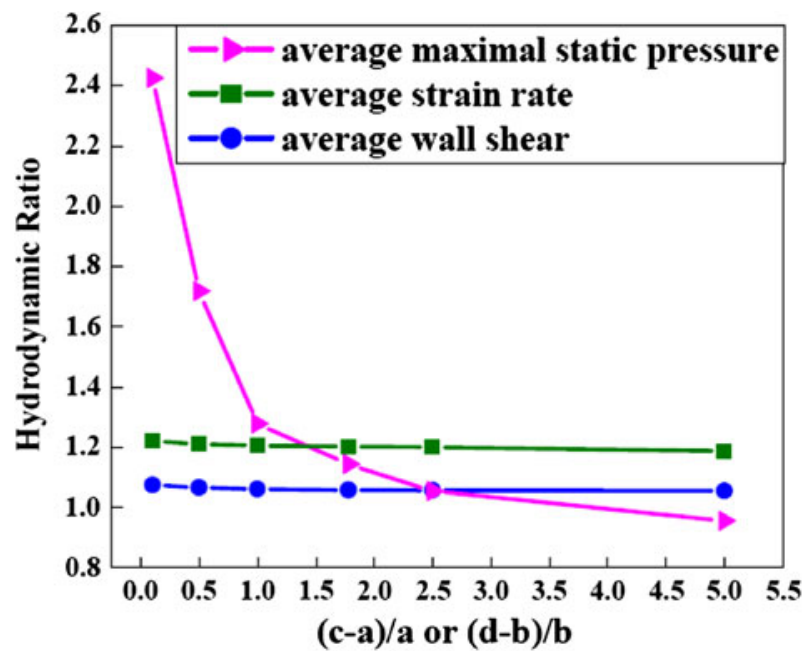

FIGURE 5. Impact of cell spacing on fluid dynamics around a cell micropatterned as circle-shaped cylinder at $2 \mu \mathrm{L} / \mathrm{min}$. Here, cell spacing was defined as a ratio of $(c-a) / a$ or $(d-b) / b$ where $a, b, c$, and $d$ represented as the dimensions of a cell and a unit, respectively (cf. Figure 1e). Data are presented as the hydrodynamic ratios of average maximal static pressure (pink line), shear stress (blue line), or strain rate (green line) with a cell to that without a cell.

TABLE 4. Calculated coefficients of $\alpha, \beta$, and $\gamma$ for different micropatterns. $^{a}$

\begin{tabular}{lcccccc}
\hline Parameters & Cir & El2 & El3 & Cub & Rec & No \\
\hline$\alpha$ & 2.77 & 2.77 & 4.85 & 3.46 & 5.20 & 1.00 \\
$\beta$ & 2.08 & 2.08 & 5.54 & 2.77 & 6.93 & - \\
$\gamma$ & 3.46 & 3.46 & 4.85 & 4.16 & 5.89 & 2.42 \\
\hline
\end{tabular}

${ }^{a}$ All the relative errors are less than 0.35 . Here the relative error is defined as the percentage of computational maximal error to computational average value.

Cub-patterned chambers. In addition, each length varies from pattern to pattern. As shown in Table 4, $L_{\text {inlet }}$ is 2.77- (Cir and El2), 4.85- (El3), 3.46- (Cub), and 5.20 -fold $(R e c)$, respectively, higher than those in a cell-free chamber ( $c f$. Supplementary Materials), implying that a much longer entrance distance is required for a fully developed flow in $R e c$ - and El3-patterned chamber. In the current study, $L_{\text {outlet }}$ is found to be greater than $L_{\text {inlet }}$, suggesting that the hydrodynamic development length of outlet is extended when the ratio of cell length to width is greater than 3.0 in Rec- and El3-patterned chambers.

Figure 6 shows the average static pressure, shear stress, and strain rate on cell surface at $2 \mu \mathrm{L} / \mathrm{min}$ when the hydrodynamic development lengths of inlet (blue lines), outlet (pink lines), or wall (green lines) are shortened to $100 \mu \mathrm{m}$ from a sufficient length of $2000 \mu \mathrm{m}$ (red lines). In order to give a whole picture of the distribution of flow field parameters in flow chamber, 14 values of average shear stress as well as 

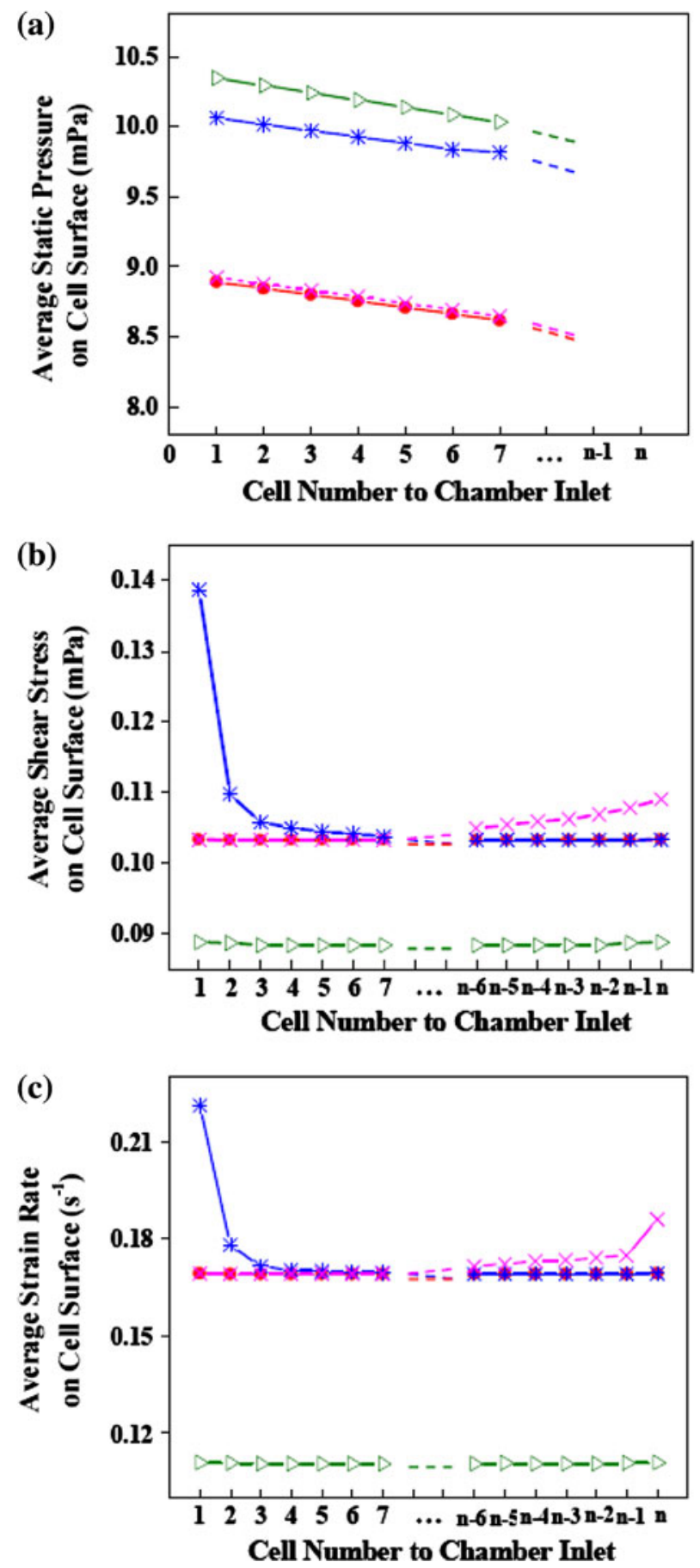

FIGURE 6. Fluid dynamics comparisons of average static pressure (a), shear stress (b), and strain rate (c) around circleshaped cylinder at $2 \mu \mathrm{L} / \mathrm{min}$, in which the average values of 1 , 2 , to 7 in blue line showed the corresponding results in case that development inlet length $L_{\text {inlet }}$ was shortened to $100 \mu \mathrm{m}$, those values of $n-6, n-5$ to $n$ in pink line when development outlet length $L^{\prime}$ outlet to $100 \mu \mathrm{m}$, those values of 1, 2-7 in green line when development wall length $L_{\text {wall }}^{\prime}$ to $100 \mu \mathrm{m}$. Furthermore, other seven data in the same line were obtained under adequate development length, i.e., $L_{\text {inlet }}^{\prime}=L_{\text {outlet }}^{\prime}=$ $L_{\text {wall }}^{\prime}=2000 \mu \mathrm{m}$. $n$ was denoted as the total number of cells in one row in the chamber. Dash lines are drawn just for explaining the variational tendencies of those parameters along the flow direction. strain rate were shown. For example, the average values of 1,2 , to 7 close to inlet in blue line indicated the corresponding results in case that development inlet length $L_{\text {inlet }}$ was shortened to $100 \mu \mathrm{m}$, while other data of $n-6$, and $n-5$ to $\mathrm{n}$ close to outlet were obtained under adequate development length, i.e., $L_{\text {inlet }}^{\prime}=$ $L_{\text {outlet }}^{\prime}=L_{\text {wall }}^{\prime}=2000 \mu \mathrm{m}$. The dash lines were drawn just for explaining the variational tendency of those parameters along the flow direction. It can be seen that the side-effect of insufficient hydrodynamic development length is evident. Average values of those parameters vary remarkably. Specifically, static pressure varies slightly $(0.4 \%)$ when outlet length is shortened, but increases significantly $(13.2 \%$ and $16.3 \%$, respectively) when inlet and wall lengths are shortened (Fig. 6a), indicating that the static pressure, though declining linearly in all the cases, is more sensitive to the changes of inlet and wall lengths. Shear stress (Fig. 6b) or strain rate (Fig. 6c), however, changes in a different way. The shear stress and strain rate when $L_{\text {wall }}^{\prime}=2000 \mu \mathrm{m}\left(0.10 \mathrm{mPa}\right.$ and $\left.0.17 \mathrm{~s}^{-1}\right)$ (red line) are relatively higher than that when $L_{\text {wall }}^{\prime}=$ $100 \mu \mathrm{m}\left(0.09 \mathrm{mPa}\right.$ and $\left.0.11 \mathrm{~s}^{-1}\right)$ (green lines), whereas asymmetric distribution is observed with much higher values at the entrance $\left(0.14 \mathrm{mPa}\right.$ and $\left.0.22 \mathrm{~s}^{-1}\right)$ when $L_{\text {inlet }}^{\prime}=100 \mu \mathrm{m}$ (blue lines) or at the exit $(0.11 \mathrm{mPa}$ and $0.19 \mathrm{~s}^{-1}$ ) when $L_{\text {outlet }}^{\prime}=100 \mu \mathrm{m}$ (pink lines). Furthermore, Fig. 6 shows that when cells existed starting at $100 \mu \mathrm{m}$ away from inlet (blue line), major difference in shear stress, as well as strain rate and static pressure occurred for the cell numbers from 1 to 7 , comparing with the case of cells appearing at $2000 \mu \mathrm{m}$ away from inlet (red line). Because cellular spacing is $100 \mu \mathrm{m}$, it means that when $L_{\text {inlet }}^{\prime}$ increases to sevenfold, significant change in shear stress is resulted as shown in Fig. 6. Taken together, these results have demonstrated that hydrodynamic parameters are sensitive to the hydrodynamic development lengths.

\section{Effect of the Orientation of Inlet Velocity Vector}

While the above numerical calculations are based on the orientation of inlet velocity vector being normal to entrance section, as used in a series of flow chambers, $4,11,16,31,40$ different orientations of inlet velocity vector have also been applied in other flow chambers. ${ }^{9,20,27}$ In this article, the impact of two alternative orientations of inlet velocity vector on flow field has been tested: one is $45^{\circ}$ relative to height-direction in $x-z$ plane (Fig. 7a), and the other is $45^{\circ}$ relative to width-direction in $x-y$ plane (Fig. 7b). Figure 7a illustrates the velocity distribution at intermediate principle plane along chamber width when inlet velocity is $45^{\circ}$ relative to the direction of length. It has been observed that flow 
(a)
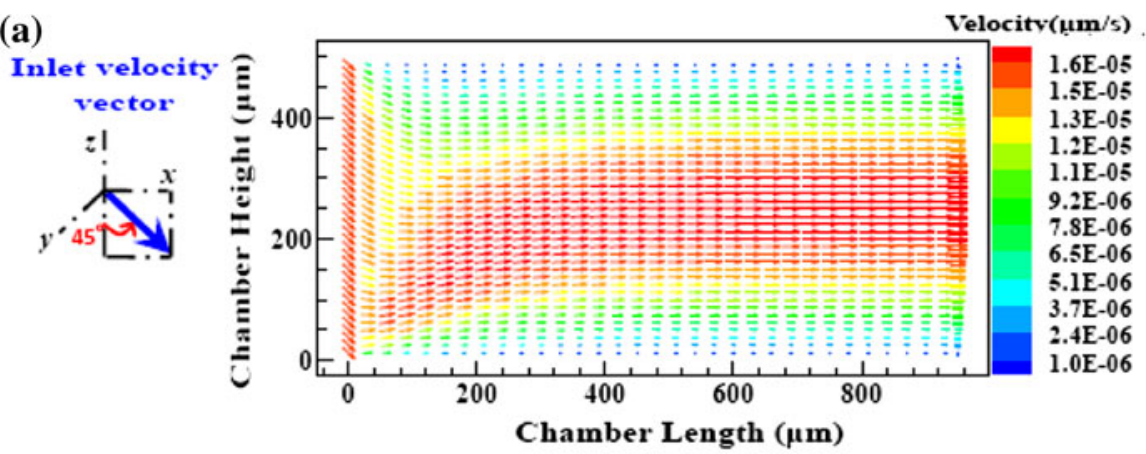

(b)
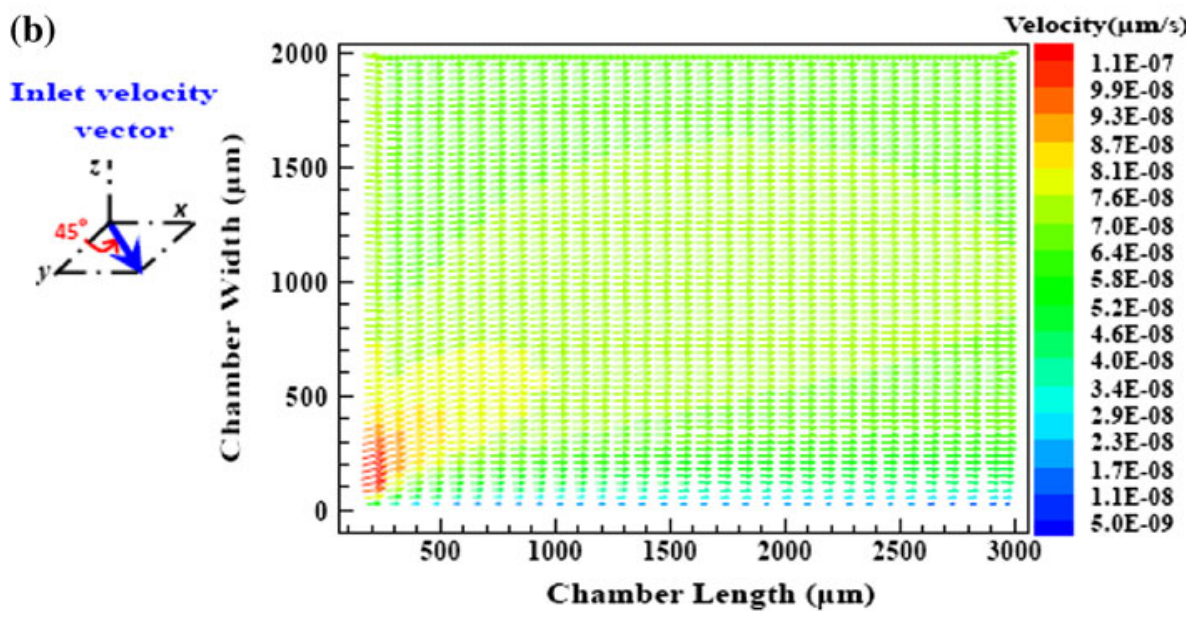

FIGURE 7. Velocity profile at the intermediate principle plane of the chamber at $2 \mu \mathrm{L} / \mathrm{min}$ with inlet velocity vector orienting along $45^{\circ}$ relative to the direction of height (a), or width (b).

TABLE 5. Dependence of coefficients $\alpha, \beta$, and $\gamma$ on inlet velocity vector. ${ }^{a}$

\begin{tabular}{lccc}
\hline Orientation of inlet velocity & $\alpha$ & $\beta$ & $\gamma$ \\
\hline $45^{\circ}$ relative to height direction & 3.46 & 2.08 & 4.16 \\
$45^{\circ}$ relative to width direction & 3.81 & 2.08 & 4.16 \\
\hline
\end{tabular}

${ }^{a}$ The relative error was 0.35 . Here the relative error is defined as the percentage of computational maximal error to the computational average value.

drifts off the main stream at inlet region and takes a relatively long distance to develop into a fully developed flow as compared to the flow that is normal to the inlet section, suggesting that $L_{\text {inlet }}$ and $L_{\text {wall }}$ are increased in this case. Similar distribution has also been observed with flow velocity at cross section on the top of a cell (a height of $0.5 \mu \mathrm{m}$ ) along chamber height when inlet velocity is $45^{\circ}$ relative to direction of the width (Fig. 7b), even though the $L_{\text {inlet }}$ and $L_{\text {wall }}$ are not elongated as much as those in Fig. 7a. Table 5 summarizes the three coefficients $\alpha, \beta$, and $\gamma$ with different orientations of inlet velocity vector in a Cir-patterned chamber, which results in that $L_{\text {inlet }}$ and $L_{\text {wall }}$ are enhanced by 20.2 $37.5 \%$ but $L_{\text {outlet }}$ remains unchanged.

\section{DISCUSSION}

Parallel-plate chambers are frequently used to examine the mechanotransduction response of cell monolayer to a constant shear stress or rate. They also serve as bioreactors for cell growth under a controllable mass transportation and nutrient supply. In this study, a novel bioreactor with micropatterned cells to isolate the cellular responses at single cell level has been proposed. Our goal is to quantify the shear stress and strain rate around individual cells via fluid dynamics analysis for preventing the side-effect of excessive or inhomogeneous shear flow from biological responses of individual cells, to visualize the entire flow field in flow chamber, and to define the geometric and fluidic dependence of a fully developed flow. The knowledge gained from this study is undoubtedly helpful for specifying the flow chamber approach and optimizing the design of cell patterns and flow field in $3 \mathrm{D}$ scaffold or bioreactor for cell/tissue growth. It might be also meaningful when long-term cell culture is required in the bioreactor, since the accumulative difference in mass transport and nutrient supply induced by different flow between the cells close to inlet and outlet mediates the distinct cell proliferation. 
To mimic the cell morphology in various biologic processes, five types of micropatterned "virtual cells" with different shapes and dimensions have been used in this study. The circle-shaped pattern represents a seeded cell without spreading, and the ellipse-pattern (1:2 or 1:3) mimics the cells at different spreading levels, whereas the cubic or rectangular pattern serves as control. A mechanical model is proposed and simplified in the micropatterned flow chamber or bioreactor using Eq. (1). Fluid mechanics analyses were done using CFD calculations to test the impacts of geometry of cell pattern, flow flux, cellular spacing, and orientation of inlet velocity vector on the flow field in interstitial space around the cells. Numerical calculations provide the estimation of hydrodynamic parameters on micropatterned cell surface. Appropriateness of the model and relevant approximations has also been investigated to quantify the hydrodynamic development length by comparison with those obtained from an approximation or an analytic solution (cf. Supplementary Materials). Mesh-independence of numerical calculations in a mesh size ranging from 932 to 3844 surface elements per cell provides the insightful condition for flow mechanics analyses. For instance, the error of maximal velocity in the local field was less than $0.01 \%$ when the number of surface elements for a circle cell varied from 2916 to 3785, whereas the error appeared to be more than $0.1 \%$ when the number of elements was reduced to 565 . Our results indicate that the novel bioreactor is reasonably proposed from the viewpoint of flow field.

To determine whether a bioreactor is appropriate for cell growth, shear stress is one of the key indicators that ensure reasonable distribution of mass transportation and nutrient supply, since physiological shear stress along endothelium in the blood vessels varies from 100 to $1500 \mathrm{mPa}$ in vivo. ${ }^{12,23}$ Table 6 summarizes, to the best of our knowledge, the estimated shear stresses in different bioreactors from the literature. The shear stress in a regular bioreactor has a relatively stable value in the range of $23.2-28.3 \mathrm{mPa},{ }^{4}$ whereas it varies significantly in some substrates with random patterns and even 3D scaffolds with irregular pores or channels. ${ }^{10,11,21,27,30}$ In this study, the authors demonstrated that, even in a regular bioreactor, shear stress on the cell surface varies linearly with cell shapes (Fig. 3) and patterns (Fig. 4). Moreover, a "wake effect" is visualized at inlet flux of $2 \mu \mathrm{L} / \mathrm{min}$ when the coordinates are enlarged (red lines in Figs. $8 \mathrm{~b}-8 \mathrm{c}$ ), ${ }^{39}$ indicating that shear stress or strain rate on the surface of first and last cells in a row is greater than those of the middle ones. This effect is also observed when the inlet flux reaches $500 \mu \mathrm{L} / \mathrm{min}$ (blue lines) with a slight nonlinearity that average shear stress or strain rate decreases gradually along streamline direction (Figs. 8b-8c). The observed difference in shear stress or strain rate is quite small $(<0.8 \%)$ under small $R e$ $(\leq 5.83)$ and low cell height $(0.5 \mu \mathrm{m})$ in this study, though the "wake effect" with the nature of nonlinearity induces significant variations under greater $R e$ and higher cell height. This may explain why the impact of flow field on biological responses of the cells near inlet or outlet is different from those on cells in the middle. On the other hand, the static pressure, i.e., the maximal pressure of 54.0 and $37.6 \mathrm{~Pa}$ for cap cement and glass, respectively, is hard to control in an irregular bioreactor. ${ }^{30}$ However, in a regular bioreactor exemplified in this study, the pressure is well controlled with a low value of $2.26 \mathrm{~Pa}$, and the average pressures on cell surface are in agreement with each other at both 2 and $500 \mu \mathrm{L} / \mathrm{min}$ (Fig. 8a). Our findings such as the linear dependence of hydrodynamic parameters within ATR (Figs. 4a-4c) and on cell spacing (Fig. 5) are helpful for optimizing the flow field inside the chamber and the shear stress on cell surface.

Another key indicator for bioreactor design requirement is to maintain a fully developed flow inside the chamber. A set of empirical equations (Eqs. $(3 a-3 c))$ and calculated coefficients (Table 4) are used

TABLE 6. Comparison of shear stress on cell surface calculated for different bioreactors.

\begin{tabular}{|c|c|c|c|c|c|}
\hline \multirow[b]{2}{*}{ Configuration } & \multicolumn{2}{|c|}{ Shear stress $(\mathrm{mPa})$} & \multirow[b]{2}{*}{ Inlet flux ( $\mu \mathrm{L} / \min )$} & \multirow[b]{2}{*}{ Viscosity (mPa s) } & \multirow[b]{2}{*}{ Literatures } \\
\hline & Average & Maximum & & & \\
\hline Irregular geometry $w / o$ cells & 3.48 & 40.0 & 500 & 0.80 & Ref. 10 \\
\hline Irregular geometry w/o cells & 2.64 & 13.0 & 300 & 0.81 & Ref. 11 \\
\hline Irregular geometry w/o cells & - & $\begin{array}{l}37.6 \text { (cap cement) } \\
46.6 \text { (glass) }\end{array}$ & 47.1 & $\begin{array}{l}0.70 \\
1.45\end{array}$ & Ref. 30 \\
\hline Irregular geometry $w / o$ cells & $4.0-18.0$ & 18.0 & 3000 & - & Ref. 21 \\
\hline Regular geometry w/o cells & 23.2 & 27.0 & 500 & 0.82 & Ref. 4 \\
\hline Regular geometry w/o cells & - & 220 & 710 & 0.69 & Ref. 27 \\
\hline Regular geometry w/o cells & 22.5 & 22.5 & 500 & 0.69 & Analytic solution $^{\mathrm{a}}$ \\
\hline Regular geometry $w /$ circle cells & 23.1 & 28.3 & 500 & 0.69 & Numerical calculation $^{\mathrm{b}}$ \\
\hline
\end{tabular}

a Obtained from Supplementary Materials; ${ }^{b}$ Calculated using Eqs. (1)-(3a, 3b, 3c). 
(a)

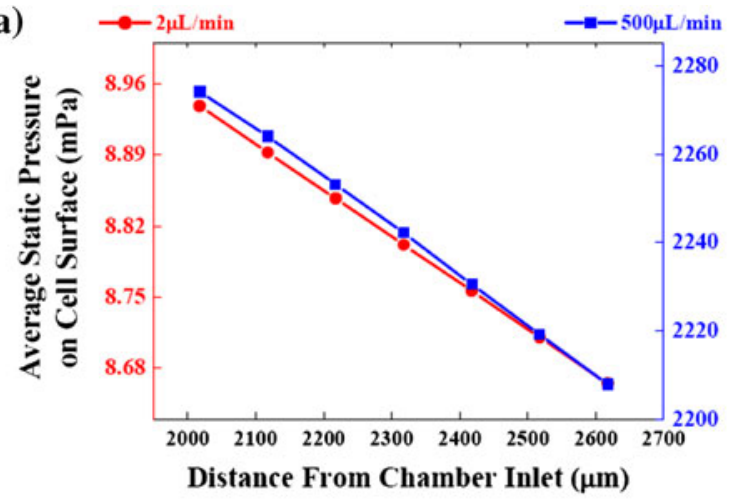

(b)

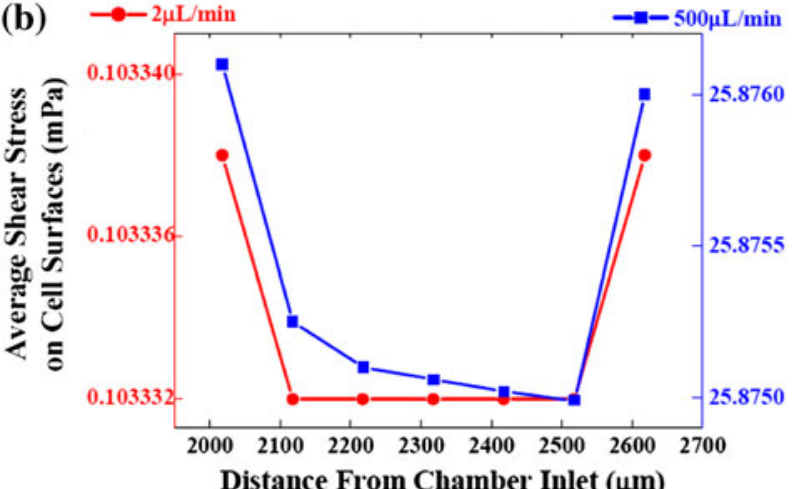

(c)

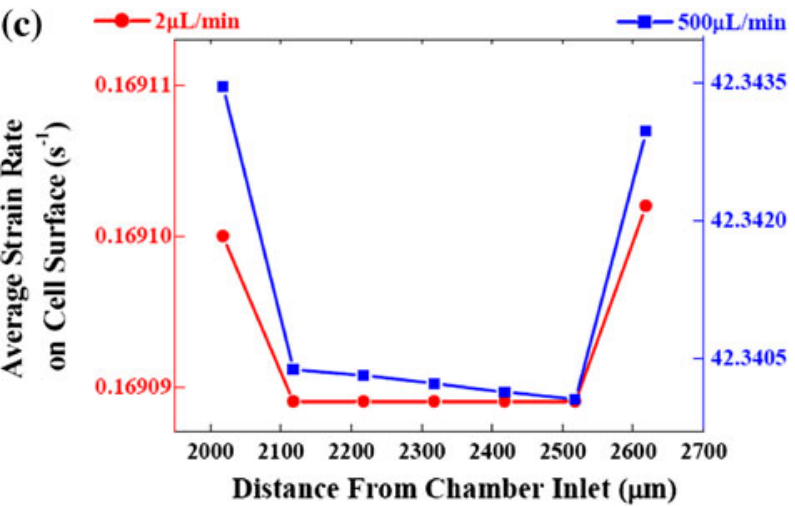

FIGURE 8. Fluid dynamics comparisons of average static pressure (a), shear stress (b), and strain rate (c) for a cell micropatterned as circle-shaped cylinder at 2 (red lines) and 500 (blue lines) $\mu \mathrm{L} / \mathrm{min}$. The length of fully developed flow was set to be $2000 \mu \mathrm{m}$ from inlet or outlet.

TABLE 7. Comparisons of hydrodynamic wall length calculated for different bioreactors. ${ }^{a}$

\begin{tabular}{lccrl}
\hline Configuration & $\begin{array}{r}L_{\text {inlet }} \\
(\mathrm{mm})\end{array}$ & $\begin{array}{c}L_{\text {outlet }} \\
(\mathrm{mm})\end{array}$ & $\begin{array}{r}L_{\text {wall }} \\
(\mathrm{mm})\end{array}$ & \multicolumn{1}{c}{ Literatures } \\
\hline W/o cells & 1.4 & 1.4 & 2.1 & Ref. 9 \\
W/o cells & 3.4 & - & 8.3 & Analytic solution \\
W/circle cells & 9.5 & 7.1 & 11.9 & Numerical calculation $^{\mathrm{c}}$ \\
\hline
\end{tabular}

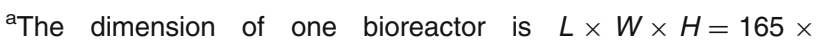
$76 \times 0.254 \mathrm{~mm}$, and the pre-set $R e=33.1$ and $1.0 \%$ criterion of error control are adapted from Chung et al. ${ }^{9}$; ${ }^{\mathrm{b}}$ Obtained from Supplementary Materials; ' Calculated using Eqs. (1)-(3a, 3b, 3c). to estimate $L_{\text {inlet }}, L_{\text {outlet, }}$ and $L_{\text {wall }}$, which are determined by $R e$ value and cell pattern (shape, dimension, and spacing). The calculated $L_{\text {inlet }}, L_{\text {outlet }}$, and $L_{\text {wall }}$ are 5.1-, 6.8-, and 5.6-fold, respectively, which are higher than those estimated previously in the absence of cells, ${ }^{9}$ viz., 1.4-, 2.8-, and 1.4-fold, respectively, which in turn are higher than those estimated from the analytic solution in Table 7, implying that enlarged hydrodynamic development length is required to maintain the fully developed flow around micropatterned cells within ATR. The impacts of the length on flow field (Fig. 6) and the outcome with different orientation of inlet velocity vector (Table 5 and Fig. 7) and different cell spacings (Fig. 5) indicate that the distances from inlet or outlet to the region of interest and the flow directions at inlet are crucial for quantifying the biological responses of cells to shear flow in a flow bioreactor.

In summary, to define the flow field on isolated cells, fluid dynamics analysis for a novel flow bioreactor has been conducted, which is beneficial for a better understanding of the cellular mechanotransduction at single cell level. Combined with relevant methods such as "artificial surface roughness elements",37,38 that are able to evaluate the average flow field within multiple cells adhering on a substrate, the future study will be able to elucidate the impact of surface friction induced by the roughness and microtopology of surfaces of cells such as cilia or pseudopods. Moreover, some limitations existing in the current study need to be addressed in future studies. For example, the deformation of cells, which affects the flow field, should be taken into account. Moreover, the estimated hydrodynamic development lengths based on the empirical equations may vary for other types of bioreactors.

\section{ELECTRONIC SUPPLEMENTARY MATERIAL}

The online version of this article (doi:10.1007/ s10439-011-0250-4) contains supplementary material, which is available to authorized users.

\section{ACKNOWLEDGMENTS}

The authors are grateful to Xin Wang, Yunfeng $\mathrm{Wu}$, and Yabin Zhai for computational assistance. This study was supported by the following grants: the Natural Science Foundation of China, \#30730032 and \#30870606; Knowledge Innovation Program of CAS, \#KJCX2-YW-L08; the National Key Basic Research Foundation of China, \#2006CB910303; and the National High Technology Research and Development Program of China, \#2007AA02Z306. 


\section{CONFLICT OF INTEREST STATEMENT}

No conflict of interested is assigned to the manuscript.

\section{REFERENCES}

${ }^{1}$ Arnsdorf, E. J., P. Tummala, R. Y. Kwon, and C. R. Jacobs. Mechanically induced osteogenic differentiation - the role of RhoA, ROCKII and cytoskeletal dynamics. J. Cell Sci. 122:546-553, 2009.

${ }^{2}$ Atkinson, B., Mp. Brockleb, C. C. H. Card, and J. M. Smith. Low Reynolds number developing flows. AIChE J. 15(4):548-553, 1969

${ }^{3}$ Bao, X., C. Lu, and J. A. Frangos. Temporal gradient in shear but not steady shear stress induces PDGF-A and MCP-1 expression in endothelial cells: role of NO, NF kappa B, and egr-1. Arterioscler. Thromb. Vasc. Biol. 19(4):996-1003, 1999.

${ }^{4}$ Boschetti, F., M. T. Raimondi, F. Migliavacca, and G. Dubini. Prediction of the micro-fluid dynamic environment imposed to three-dimensional engineered cell systems in bioreactors. J. Biomech. 39(3):418-425, 2006.

${ }^{5}$ Butcher, J., and R. M. Nerem. Valvular endothelial cells regulate the phenotype of interstitial cells in co-culture: effects of steady shear stress. Tiss. Eng. 12(4):905-915, 2006.

${ }^{6}$ Chen, R. Y. Flow in entrance region at low Reynoldsnumbers. J. Fluid Eng.-T ASME 95(1):153-158, 1973.

${ }^{7}$ Chen, C. S., J. L. Alonso, E. Ostuni, G. M. Whitesides, and D. E. Ingber. Cell shape provides global control of focal adhesion assembly. Biochem. Biophys. Res. Commun. 307(2):355-361, 2003

${ }^{8}$ Chotard-Ghodsnia, R., O. Haddad, A. Leyrat, A. Drochon, C. Verdier, and A. Duperray. Morphological analysis of tumor cell/endothelial cell interactions under shear flow. J. Biomech. 40(2):335-344, 2007.

${ }^{9}$ Chung, B. J., A. M. Robertson, and D. G. Peters. The numerical design of a parallel plate flow chamber for investigation of endothelial cell response to shear stress. Comput. Struct. 81(8-11):535-546, 2003

${ }^{10}$ Cioffi, M., F. Boschetti, M. T. Raimondi, and G. Dubini. Modeling evaluation of the fluid-dynamic microenvironment in tissue-engineered constructs: a micro-CT based model. Biotechnol. Bioeng. 93(3):500-510, 2006.

${ }^{11}$ Cioffi, M., J. Kuffer, S. Strobel, G. Dubini, I. Martin, and D. Wendt. Computational evaluation of oxygen and shear stress distributions in 3D perfusion culture systems: macroscale and micro-structured models. J. Biomech. 41(14): 2918-2925, 2008.

${ }^{12}$ Davies, P. F. Flow-mediated endothelial mechanotransduction. Phys. Rev. 75(3):519-560, 1995.

${ }^{13}$ De Paola, N., M. A. Gimbrone, Jr., P. F. Davies, and C. F. Dewey, Jr. Vascular endothelium responds to fluid shear stress gradients. Arterioscler. Thromb. Vasc. Biol. 12(11): 1254-1257, 1992.

${ }^{14}$ Fritton, S. P., and S. Weinbaum. Fluid and solute transport in bone: flow-induced mechanotransduction. Annu. Rev. Fluid Mech. 41:347-374, 2009.

${ }^{15}$ Fung, Y. C., and S. Q. Liu. Elementary mechanics of the endothelium of blood vessels. J. Biomech. Eng. 115(1):1-12, 1993.

${ }^{16}$ Huo, B., X. L. Lu, C. T. Hung, K. D. Costa, Q. B. Xu, G. M. Whitesides, and X. E. Guo. Fluid flow induced calcium response in bone cell network. Cell. Mol. Bioeng. 1:58-66, 2008.

${ }^{17}$ Kadohama, T., K. Nishimura, Y. Hoshino, T. Sasajimaand, and B. E. Sumpio. Effects of different types of fluid shear stress on endothelial cell proliferation and survival. J. Cell. Physiol. 212(1):244-251, 2007.

${ }^{18}$ Khismatullin, D. B., and G. A. Truskey. A 3D numerical study of the effect of channel height on leukocyte deformation and adhesion in parallel-plate flow chambers. Microvasc. Res. 68(3):188-202, 2004.

${ }^{19}$ Leclerc, E., B. David, L. Griscom, B. Lepioufle, T. Fujii, P. Layrolle, and C. Legallaisa. Study of osteoblastic cells in a microfluidic environment. Biomaterials 27(4):586-595, 2006.

${ }^{20}$ Levitan, I., B. P. Helmke, and P. F. Davies. A chamber to permit invasive manipulation of adherent cells in laminar flow with minimal disturbance of the flow field. Ann. Biomed. Eng. 28(10):1184-1193, 2000.

${ }^{21} \mathrm{Li}$, D., T. Tang, J. Lu, and K. Dai. Effects of flow shear stress and mass transport on the construction of a largescale tissue-engineered bone in a perfusion bioreactor. Tiss. Eng. A 15(10):2773-2783, 2009.

${ }^{22}$ Liu, S. Q., M. Yen, and Y. C. Fung. On measuring the third dimension of cultured endothelial cells in shear flow. Proc. Nat. Acad. Sci. 91(19):8782-8786, 1994.

${ }^{23}$ Malek, A. M., S. L. Alper, and S. Izumo. Hemodynamic shear stress and its role in atherosclerosis. J. Am. Med. Assoc. 282(21):2035-2042, 1999.

${ }^{24}$ Mattiussi, S., C. Lazzari, S. Truffa, A. Antonini, S. Soddu, M. C. Capogrossi, and C. Gaetano. Homeodomain interacting protein kinase 2 activation compromises endothelial cell response to laminar flow: protective role of p21(waf1,cip1,sdi1). PLoS ONE 4(8):e6603, 2009.

${ }^{25}$ Morton, K. W., and E. Suli. Finite volume methods and their analysis. IMA J. Numer. Anal. 11(2):241-260, 1991.

${ }^{26}$ Myong, H. K., and T. Kobayashi. Prediction of 3-dimensional developing turbulent-flow in a square duct with an anisotropic low-Reynolds-number Kappa-Epsilon Model. J. Fluid Eng.-T ASME 113(4):608-615, 1991.

${ }^{27}$ Provin, C., K. Takano, Y. Sakai, T. Fujii, and R. Shirakashi. A method for the design of 3D scaffolds for high-density cell attachment and determination of optimum perfusion culture conditions. J. Biomech. 41:1436-1449, 2008.

${ }^{28}$ Rangaswami, H., N. Marathe, S. Zhuang, Y. Chen, J. C. Yeh, J. A. Frangos, G. R. Boss, and R. B. Pilz. Type II cGMP-dependent protein kinase mediates osteoblast mechanotransduction. J. Biol. Chem. 284(22):14796-14808, 2009.

${ }^{29}$ Robinson, A. J., D. Kashanin, F. O’Dowd, K. Fitzgerald, V. Williams, and G. M. Walsh. Fluvastatin and lovastatin inhibit granulocyte macrophage-colony stimulating factorstimulated human eosinophil adhesion to inter-cellular adhesion molecule-1 under flow conditions. Clin. Exp. Allergy 39(12):1866-1874, 2009.

${ }^{30}$ Sandino, C., J. A. Planell, and D. Lacroix. A finite element study of mechanical stimuli in scaffolds for bone tissue engineering. J. Biomech. 41(5):1005-1014, 2008.

${ }^{31} \mathrm{Su}$, S. S., and G. W. Schmid-Schonbein. Internalization of formyl peptide receptor in leukocytes subject to fluid stresses. Cell. Mol. Bioeng. 3:20-29, 2010.

${ }^{32}$ Sun, S. J., Y. X. Gao, N. J. Shu, Z. M. Tang, Z. L. Tao, and M. Long. A novel counter sheet-flow sandwich cell culture device for mammalian cell growth in space. Microgravity Sci. Technol. 20(2):115-120, 2008. 
${ }^{33}$ Sun, H., C. K. Aidun, and U. Egertsdotter. Effects from shear stress on morphology and growth of early stages of Norway spruce somatic embryos. Biotechnol. Bioeng. 105(3): 588-599, 2009.

${ }^{34}$ Swartz, M. A., and M. E. Fleury. Interstitial flow and its effects in soft tissues. Annu. Rev. Biomed. Eng. 9:229-256, 2007.

${ }^{35}$ Szymanski, M. P., E. Metaxa, H. Meng, and J. Kolega. Endothelial cell layer subjected to impinging flow mimicking the apex of an arterial bifurcation. Ann. Biomed. Eng. 36(10):1681-1689, 2008.

${ }^{36}$ ASME Steam Tables, 3rd ed., Am Soc Mech Engrs, 1977.
${ }^{37}$ Webb, R. L. Single-phase heat transfer, friction, and fouling characteristics of three-dimensional cone roughness in tube flow. Int. J. Heat Mass Transf. 52:2624-2631, 2009.

${ }^{38}$ Webb, R. L., and N. H. Kim. Principles of Enhanced Heat Transfer, 2nd ed. New York: Taylor \& Francis, 2005.

${ }^{39} \mathrm{Wu}, \mathrm{W}$. Y., and H. Mei. The oseen flow of finite clusters of spheres and the wake effect on the drag factor. Acta Mech. Sinica 2(4):289-304, 1986.

${ }^{40}$ You, L., S. Temiyasthit, S. R. Coyer, A. J. García, and C. R. Jacobs. Bone cells grown on micropatterned surfaces are more sensitive to fluid shear stress. Cell. Mol. Bioeng. $1: 182-188,2008$ 